\title{
Diabetes Insipidus: An Unusual Cause of Urinary Frequency During Pregnancy
}

\author{
Darryl Potyk, MD, FACP, and Danielle Towne, MD
}

Urinary frequency during pregnancy is common. The most common causes are compression of the urinary bladder by the gravid uterus, urinary tract infections, and hyperglycemia. Diabetes insipidus is an unusual cause of urinary frequency during pregnancy but should be considered when patients frequently void large volumes of urine. Diabetes insipidus can be a preexisting disease (clinically overt or subclinical) or can be associated with pregnancy as a result of excessive placental vasopressinase activity. We describe a case of diabetes insipidus that was not diagnosed until the postpartum period and review the pertinent literature.

\section{Case Report:}

A 17-year-old woman was involved in a motor vehicle accident that resulted in closed-head trauma, intracerebral hemorrhage, and coma. At the same time she was found to be 16-weeks pregnant. Her mental status improved, and she underwent extensive rehabilitation. Her prenatal course was unremarkable, though she complained of polydipsia, polyuria, and nocturia. Her glucose tolerance test and urinalysis were both normal, and these symptoms were attributed to her pregnancy.

At 33 weeks' gestation the patient complained of nausea and vomiting. Her blood pressure was $150 /$ $100 \mathrm{~mm} \mathrm{Hg}$; she had right upper quadrant tenderness; and her platelet count was $22,000 / \mu \mathrm{L}$, aspartate aminotransferase $420 \mathrm{U} / \mathrm{L}$, and total bilirubin $1.4 \mathrm{mg} / \mathrm{dL}$. A diagnosis of preeclampsia and possible HELLP syndrome was made, and labor was induced. She was given magnesium sulfate, and she received nothing by mouth but was given intrave-

Submitted 18 September 1998.

From Internal Medicine Spokane, and the University of Washington School of Medicine (DP), Spokane; and Department of Obstetrics and Gynecology (DT), Southern California Permanente Medical Group, San Diego, California. Address reprint requests to Darryl Potyk, MD, Internal Medicine Spokane, 101 West 8th Avenue, PO Box 2555, Spokane, WA 99220-2555.

Presented in abstract form as a clinical vignette at the Society of General Internal Medicine National Meeting, Chicago, Illinois, April 23-25, 1998. nous fluids at $125 \mathrm{~mL} / \mathrm{h}$. Labor progressed rapidly, and she gave birth to a 2540 -g female infant.

During the next 24 hours she continued with intravenous magnesium and fluid restriction. Her liver function tests and platelet counts began to improve. Her urine output during labor and the postpartum period was $200 \mathrm{~mL} / \mathrm{h}$. Laboratory values 15 hours after delivery were sodium 167 $\mathrm{mEq} / \mathrm{L}$, potassium $3.6 \mathrm{mEq} / \mathrm{L}$, chloride $134 \mathrm{mEq} / \mathrm{L}$, and bicarbonate $30 \mathrm{mEq} / \mathrm{L}$. Because a laboratory error was suspected, a second sodium determination was requested, which was $171 \mathrm{mEq} / \mathrm{L}$. Her serum osmolality was $366 \mathrm{mOsm} / \mathrm{kg}$, while her urine osmolality was $156 \mathrm{mOsm} / \mathrm{kg}$. She was given 1-desmino8D-arginine-vasopressin (DDAVP), and her osmolality returned to normal within 24 hours. Serum and urine osmolality determinations were repeated 3 weeks, 6, and 12 months later, which confirmed persistent diabetes insipidus. She did not undergo a formal water-deprivation challenge, and her anterior pituitary function and oxytocin levels remained normal.

\section{Discussion}

We postulate that this patient had posttraumatic diabetes insipidus as a result of her closed-head injury. She had no symptoms predating her injury, and polyuria and polydipsia began after the injury. Traumatic diabetes insipidus has been associated with severe head trauma, as occurred in this patient. ${ }^{1,2}$ The injury damages the axons of the pituitary stalk and impairs the transport and release of vasopressin from the posterior pituitary. ${ }^{3}$ In a minority of cases there is spontaneous remission of the diabetes insipidus as axonal regeneration within the pituitary stalk occurs. ${ }^{1,2}$ Because the anterior pituitary relies on a local endocrine system rather than a direct neural connection, most patients with traumatic diabetes insipidus have preserved anterior pituitary function. Although uncommon, the incidence of posttraumatic diabetes insipidus is well documented. In a series of 196 patients with longstanding central diabetes insipidus, the most common causes are idiopathic (25\%) and head trauma 
Table 1. Causes of Long-Standing Central Diabetes Insipidus ( $\mathbf{n}-\mathbf{1 3 5})$.

\begin{tabular}{lcc}
\hline Cause & $\begin{array}{c}\text { Number of } \\
\text { Cases }\end{array}$ & $\begin{array}{c}\text { Percent of } \\
\text { Cases }\end{array}$ \\
\hline Idiopathic & 34 & 25 \\
Head trauma & 24 & 18 \\
Primary brain tumor (preoperative) & 20 & 15 \\
Primary brain tumor (postoperative) & 20 & 15 \\
Posthypophysectomy & 12 & 9 \\
Metastatic tumor & 11 & 8 \\
Nontraumatic encephalomalacia & 7 & 5 \\
Langerhans cell granulomatosis & 5 & 4 \\
Sarcoidosis & 1 & 1 \\
Ruptured cerebral aneurysm & 1 & 1 \\
\hline
\end{tabular}

Modified, with permission, from: Moses AM Streeten, DH. Disorders of the neurohypophysis. In: Fauci AS, Braunwald E, Illelbacher KJ, et al, editors. Harrison's principles of internal medicine. 14th ed. New York: McGraw-Hill, 1998:2005; Table 330-1.

Note: long-standing refers to longer than 6-months or until death.

(18\%) (Table 1). ${ }^{4}$ Diabetes insipidus has been associated with postpartum pituitary necrosis (Sheehan syndrome), but this patient had no other peripartum complications, and her anterior pituitary function was intact. ${ }^{5}$

Our patient's thirst mechanisms were intact, and up until the time of delivery, she had free access to water. Under these circumstances it is possible to maintain normal water balance and normal electrolytes because free water losses are replaced. In this setting, distinguishing between diabetes insipidus and psychogenic polydipsia can be difficult. A su- pervised water-deprivation test and documenzed response to injected vasopressin will differentwote these conditions. This patient had an informal \&्fater deprivation test when she did not have retady access to water during labor and the postpar period. Her serum and urine osmolality and ⿱ㅗㅇㅡ response to vasopressin confirmed the diagnosiș of diabetes insipidus (Figure 1).

During the prepartum period, our patient's syige toms were attributed to mechanical irritation of क्ज़e urinary bladder by the gravid uterus. She hadळึo evidence of gestational diabetes or urinary tract inffiction. Volume expansion and changes in water balaக̄ce occur normally during pregnancy and can contribijte to polydipsia and polyuria. The changes in wer balance are the result of a lowered thirst threst oild and a lowered threshold for vasopressin release. result, the osmostat is reset, and plasma osmolasty decreases by $10 \mathrm{mOsm} / \mathrm{kg}$ during the first trinfogster. $^{6,7}$

An uncommon cause of polyuria during pregnancy is transient diabetes insipidus. These ठुo conditions occur simultaneously in 2 to 6 \$ 0 of 100,000 pregnancies. ${ }^{8,9}$ Transient diabetes ins畗idus of pregnancy results from increased circulatiting vasopressinase produced by the placenta. Althowh its physiologic function is unclear, vasopressingse increases throughout pregnancy. From the 4tlsto the 38 th week there is a 1000 -fold increaseogin vasopressinase activity. ${ }^{9-11}$ As a result of increa黑ed vasopressinase activity, there are several manife $\overrightarrow{8}$ tions of diabetes insipidus during pregnaricy. Women with complete diabetes insipidus before cợn-

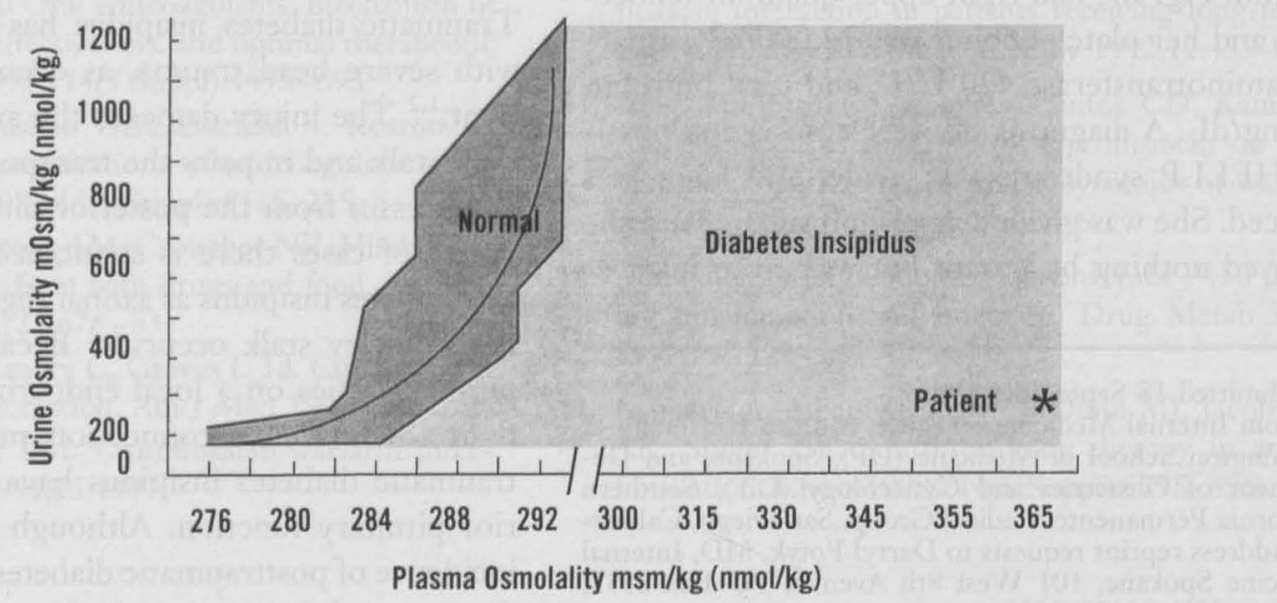

Figure 1. Relation of plasma and urinary osmolality for normal adult subjects and patients with diabetes insipidius.

490 JABFP November-December 1999 Vol. 12 No. 6 
ception have normal fertility and can have normal pregnancies. ${ }^{12}$ The increased vasopressinase activity usually results in increased vasopressin requirements during pregnancy. This change will be less apparent in women using the synthetic analogue of vasopressin, DDAVP, because substitutions in the synthetic molecule make it resistant to degradation by vasopressinase. ${ }^{10}$ Patients with previously undiagnosed subclinical diabetes insipidus could become symptomatic during pregnancy because endogenous vasopressin is degraded by vasopressinase, creating a relative vasopressin deficiency. ${ }^{13,14}$ Lastly, a small number of patients will develop transient diabetes insipidus during pregnancy solely on the basis of very high vasopressinase levels. Serum vasopressinase activity is proportional to the weight of the placenta. (In one case a patient was delivered of a placenta 2.5 times the appropriate weight for gestation.) Multiple pregnancies also show increased plasma vasopressinase activity. ${ }^{15}$

There appears to be a relation between preeclampsia and transient diabetes insipidus of pregnancy. In one recent report, all 17 cases of transient diabetes insipidus of pregnancy were associated with abnormal liver function tests; 13 of the 17 patients had hypertension, 13 had elevated uric acid levels, and 7 had proteinuria. Hepatic function decreases in preeclampsia, and this diminished function impairs vasopressinase clearance, resulting in decreased vasopressin levels and large-volume polyuria. ${ }^{16}$ This syndrome is transient because vasopressinase levels fall dramatically once the placenta has been delivered. Levels fall approximately $25 \%$ per day and become undetectable by 4 weeks. $^{10}$ The synthetic vasopressin analog DDAVP, administered subcutaneously or intravenously, is the drug of choice for any form of diabetes insipidus during pregnancy. This syndrome can recur with subsequent pregnancies. ${ }^{11}$

We have described and discussed a case of posttraumatic diabetes insipidus that was overlooked during pregnancy but diagnosed and treated postpartum. This case illustrates that the diagnosis of diabetes insipidus can be difficult to make when the patient has intact thirst mechanisms and access to water. We hope that our case discussion will increase physicians' awareness of posttraumatic diabetes insipidus and broaden their differential diagnosis of urinary frequency to include the unusual diagnosis of transient diabetes insipidus of pregnancy.

\section{References}

1. Notman DD, Mortek MA, Moses AM. Permanent diabetes insipidus following head trauma: observations on ten patients and an approach to diagnosis. J Trauma 1980;20:599-602.

2. Griffin JM, Hartley JH Jr, Crow RW, Schatten WE. Diabetes insipidus caused by craniofacial trauma. J Trauma 1976;16:979-84.

3. Crompton MR. Hypothalamic lesions following closed head injury. Brain 1971;94:165-72.

4. Moses AM, Streeten DH. Disorders of the neurohypophysis. In: Fauci AS, Braunwald E, Isselbacher KJ, et al. Harrison's principles of internal medicine. 14th ed. New York: McGraw-Hill, 1998:2003-12.

5. Schwartz AR, Leddy AL. Recognition of diabetes insipidus in postpartum hypopituitarism. Obstet Gynecol 1982;59:394-8.

6. Lindheimer MD, Barron WM, Durr J, Davison JM. Water homeostasis and vasopressin release during rodent and human gestation. Am J Kidney Dis 1987; 9:270-5.

7. Davison JM, Gilmore EA, Durr J, Robertson GL, Lindheimer MD. Altered osmotic thresholds for vasopressin secretion and thirst in human pregnancy. Am J Physiol 1984;246(1 Pt 2):F105-9.

8. Durr JA. Diabetes insipidus in pregnancy. Am J Kidney Dis 1987;9:276-83.

9. Hughes JM, Barron WM, Vance ML. Recurrent diabetes insipidus associated with pregnancy: pathophysiology and therapy. Obstet Gynecol 1989;73(3 Pt 2):462-4.

10. Durr JA, Hoggard JG, Hunt JM, Schrier RW. Diabetes insipidus in pregnancy associated with abnormally high circulating vasopressinase activity. N Engl J Med 1987;316:1070-4.

11. Barron WM, Cohen LH, Ulland LA, et al. Transient vasopressin-resistant diabetes insipidus of pregnancy. N Engl J Med 1984;310:442-4.

12. Hadi HA, Mashini IS, Devoe LD. Diabetes insipidus during pregnancy complicated by preeclampsia. A case report. J Reprod Med 1985;30:206-8.

13. Iwasaki Y, Oiso Y, Kondo K, et al. Aggravation of subclinical diabetes insipidus during pregnancy. N Engl J Med 1991;324:522-6.

14. Williams DJ, Metcalfe KA, Skingle L, Stock AI, Beedham T, Monson JP. Pathophysiology of transient cranial diabetes insipidus during pregnancy. Clin Endocrinol Oxf 1993;38:595-600.

15. Krege J, Katz VL, Bowes WA Jr. Transient diabetes insipidus of pregnancy. Obstet Gynecol Surv 1989; 44:789-95.

16. Kennedy S, Hall PM, Seymour AE, Hague WM. Transient diabetes insipidus and acute fatty liver of pregnancy. Br J Obstet Gynaecol 1994;101:387-91. 